\title{
NONLINEAR FINITE ELEMENT ANALYSIS ON LONG COLUMNS OF HIGH-STRENGTH CONCRETE-FILLED SQUARE STEEL TUBE WITH INNER CFRP CIRCULAR TUBE UNDER AXIAL LOAD
}

\author{
G.C. $\mathrm{Li}^{1{ }^{1,}, \text { C.Y. } \mathrm{Di}^{2}}{ }^{2}$, L. Tian ${ }^{2}$ and C. Fang ${ }^{2}$ \\ ${ }^{1}$ Professor, School of Civil Engineering, Shenyang Jianzhu University, Shenyang, China \\ ${ }^{2}$ Postgraduate, School of Civil Engineering, Shenyang Jianzhu University, Shenyang, China \\ *(Corresponding author: E-mail: liguochang0604@sina.com)
}

Received: 13 December 2011; Revised: 18 May 2012; Accepted: 23 May 2012

\begin{abstract}
The concrete-filled square steel tubular structure has been applied wildly in the practical projects around the world. To install CFRP into the column is beneficial not only to overcome the disadvantages of the high-strength concrete, but also to improve the bearing capacity and the stability of the concrete-filled square steel tube. This paper adopts finite element analysis software ABAQUS 6.7 to make nonlinear finite element analysis on a large number of long columns of high-strength concrete-filled square steel tube with inner CFRP circular tube subjected to axial compression. The analysis results are verified by the tests. In addition, the load-axial strain curves in the whole process are calculated and analyzed, and they are divided into 4 segments: elastic phase, plastic phase, descending phase and rebound phase. Based on the curves of load-axial strain, the stresses analysis on the core concrete, CFRP tube and square steel tube are conducted. The results of finite element simulation analysis show the destruction of long columns subjected to axial compression are all buckling failure. It indicates that slenderness ratios are the key to decide the type of buckling failure for long columns under axial compressive loading. The boundary slenderness ratio between elastic buckling and plastic buckling is discussed.
\end{abstract}

Keywords: ABAQUS finite element, inner CFRP circular tube, axial compression, working mechanism, boundary slenderness ratio.

\section{INTRODUCTION}

Many advantages, such as high bearing capacity, good stability, and simple type of joint available in the structure, can be shown in the concrete-filled square steel tube structure, so it is widely applied in practical engineering. Especially, the simple type of joint turns the concrete-filled square steel tubular column into a good component in frame structure. Some relative researches have been accomplished before, as shown in Cai and $\mathrm{Gu}$ [1] and Tan et al. [2]. On the basis of the theory in Han [3] and Zhong [4], some new materials are used and analyzed in the papers. Liang et al. [5] [7] investigated the strengths and behavior of short concrete filled thin-walled steel box columns with local buckling effects by nonlinear fiber element analysis, with the study of several essential effects on the stiffness, strength and ductility of high strength thin-walled CFST beam columns under combined axial load and biaxial bending, and studied the critical local and post-local buckling behavior of steel plates in concrete-filled thin-walled steel tubular beam-columns. Mohanad and Uy [8] [9] presented the experimental and theoretical studies of the behavior of hollow and concrete filled steel columns fabricated with high strength structural steel plate and subjected to biaxial bending. With the continuous development of concrete technology and new material, high-strength concrete and CFRP are used to cooperate with the steel tube and then the high-strength concrete-filled square steel tube with built-in CFRP circular tube is formed. According to $\mathrm{Li}$ et al. [10], this method can overcome effectively the weaknesses of brittleness of high-strength concrete and improve the bearing capacity and stability of concrete-filled steel tubular column. 
The CFRP circular steel tube is installed into the high-strength concrete filled square steel tube to form a new type of composite component. With the development of society and economy, there are a large number of high-rise buildings and the constructional members with big slenderness ratio which have been and will be used in practice engineering, so it is necessary to study further in the mechanical properties of the long columns. By the finite element analysis software ABAQUS 6.7, the entire process analysis on long columns $(\lambda>45)$ of concrete-filled square steel tube with inner CFRP circular tube under axial load is conducted and the working mechanism of the long columns is deeply investigated in the paper.

\section{FINITE ELEMENT MODEL}

\subsection{Constitutive Model of Materials}

\subsubsection{Steel}

In the paper, the elastic-plastic material behavior provided by ABAQUS 6.7 is applied to emulate the steel. Since the cold-formed steel tube which is divided into the corner zone and the plate zone with the different residual stress is adopted in the research, an idealized multi-liner stress-strain model proposed by Abdel-Rahman and Sivakumaran [11] is used to simulate the constitutive relation of the steel, as shown in the Figure 1. The first part of the curve is defined as the elastic stage with the Young's modulus $E_{s}=206000 \mathrm{MPa}$, and Poisson's ratio $(v)$ is taken as 0.3 .

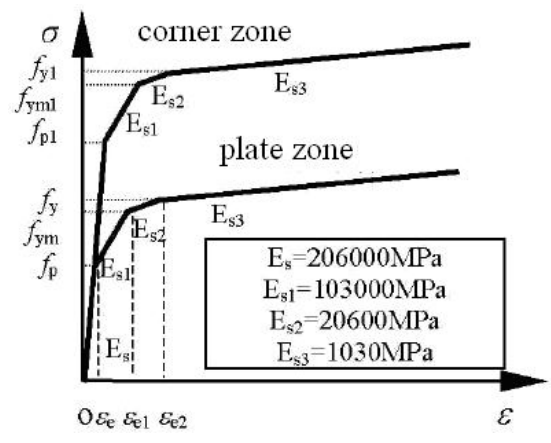

Figure 1. Idealized stress-strain curves of cold-formed steel

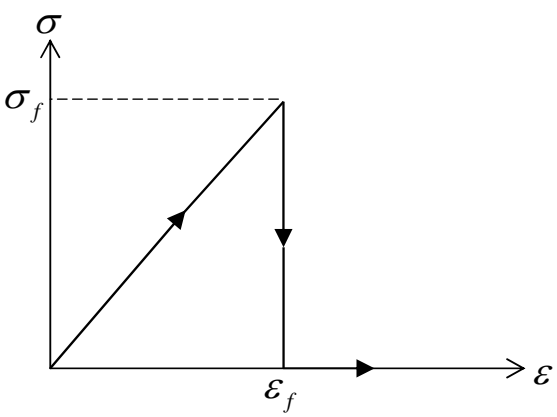

Figure 2. Stress-strain curve of CFPR

\subsubsection{CFRP}

The Lamina model provided by ABAQUS 6.7 is elected to simulate the mechanical performance of the CFPR in the elastic stage. The Hashin damage model is applied to emulation of the abrupt fracture behavior. On the basis of the previous researches, the interaction between CFRP and concrete can be neglected, since the bonding strength between CFRP and concrete is less than the strength of CFRP. Therefore, CFRP is assumed to be in the elastic state before its failure, and CFRP is ruptured and removed from the analysis owing to disability to bear load when CFRP reaches the ultimate strain. Figure 2 shows the stress-stain curve of the CFRP and the formulas of the constitutive relation are as follows:

$\varepsilon \leq \varepsilon_{\mathrm{f}}, \quad \sigma_{\mathrm{f}}=E_{\mathrm{f}} \varepsilon$

$\varepsilon>\varepsilon_{\mathrm{f}}, \quad \sigma_{\mathrm{f}}=0$ 
Where, $\sigma_{\mathrm{f}}$ is the ultimate stress of the fiber; $E_{\mathrm{f}}$ is the modulus of elasticity; $\varepsilon_{\mathrm{f}}$ is the ultimate strain.

\subsubsection{Concrete}

In the paper, the damage plastic model provided by ABAQUS 6.7 is used to emulate the concrete material. Since taking into consideration the confinement effects of the CFPR tube and steel tube on the core concrete, the stress-strain relationship of the high-strength concrete developed by Liu [12] is applied to emulate the concrete in the analysis.

\subsection{Element}

For taking into consideration the shear deformation along the thickness direction, the shell element of four nodes reduced integration scheme (S4R) is used to simulate steel. With the change of shell thickness, the method will automatically fit to the thick or thin shell theory. In order to satisfy the required accuracy, 9 integration points of Simpson theory along the thickness direction in the shell element are needed. The composite shell element of four nodes reduced integration scheme (S4R) is applied to emulate CFRP with 3 integration points of Simpson theory along the thickness direction in the shell element. The three-dimensional solid element (C3D8R) of eight nodes reduced integration scheme is used as the element model to emulate the concrete and the loading plate. In addition, the loading plate can be seen as rigid body, because it almost has no distortion in the process of experiment. The elastic modulus of the loading plate should be set largely enough and the Poisson ratio is set diminutively enough in the material properties to emulate the rigid body.

\subsection{Boundary Conditions and Mode of Loading}

For the symmetry of cylinder geometry and boundary conditions of the model, a quarter of the actual component is selected to simulate. There are symmetric boundary conditions on the two symmetric planes in the components of concrete-filled steel tube, as shown in Figure 3(a). When making nonlinear finite element analysis on long columns of concrete-filled square steel tube under axial compression, initial defects of specimen should be taken into consideration due to its large effect on the mechanical properties of long columns of high-strength concrete-filled square steel tube with built-in CFRP circular tube under axial compression. The initial defects in columns of concrete-filled steel tube belong to small eccentricity, so loading cannot be completely exerted on axle center in the process of simulation on components. The initial deflection of components should be set as thousandth length of rod (taking initial eccentricity $\mathrm{e}_{0}=\mathrm{L} / 1000$ ). The loading path is that when fixing the displacement of $\mathrm{X}, \mathrm{Z}$ direction, the line load is applied on the loading plate (the loading program is the displacement.), as shown in Figure 3 (b). 


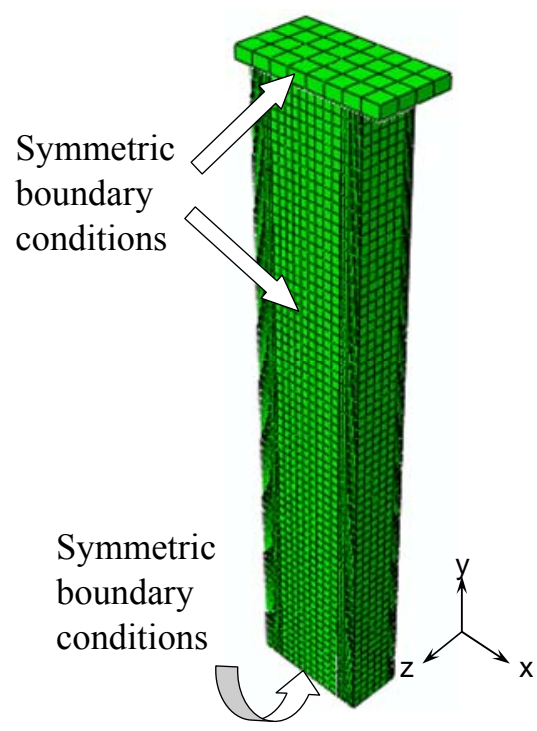

(a) Analysis Model

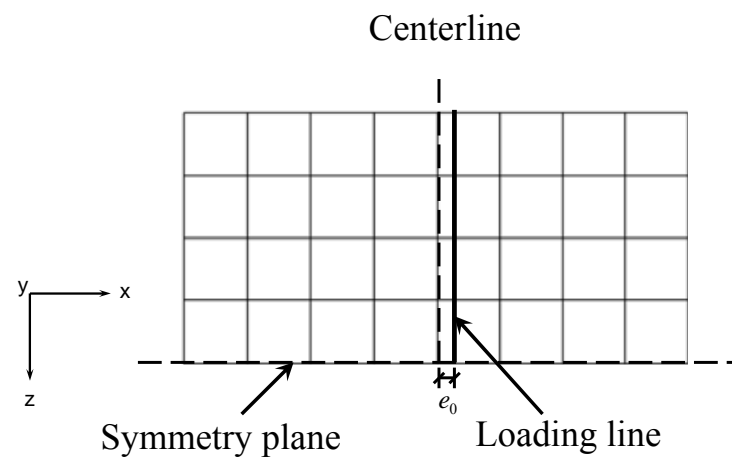

(b) Loading Path

Figure 3. Axial Compression Model of Long Columns Considering Initial Defects

\subsection{Contact}

Owing to analysis on three materials, including steel, concrete and carbon fiber, the columns of high-strength concrete-filled square steel tube with built-in CFRP circular tube studied in this paper are relatively special. Therefore, on the basis of the practical situation, the contact relation that is as simple as possible to avoid complicated contact among different materials is emulated in the paper.

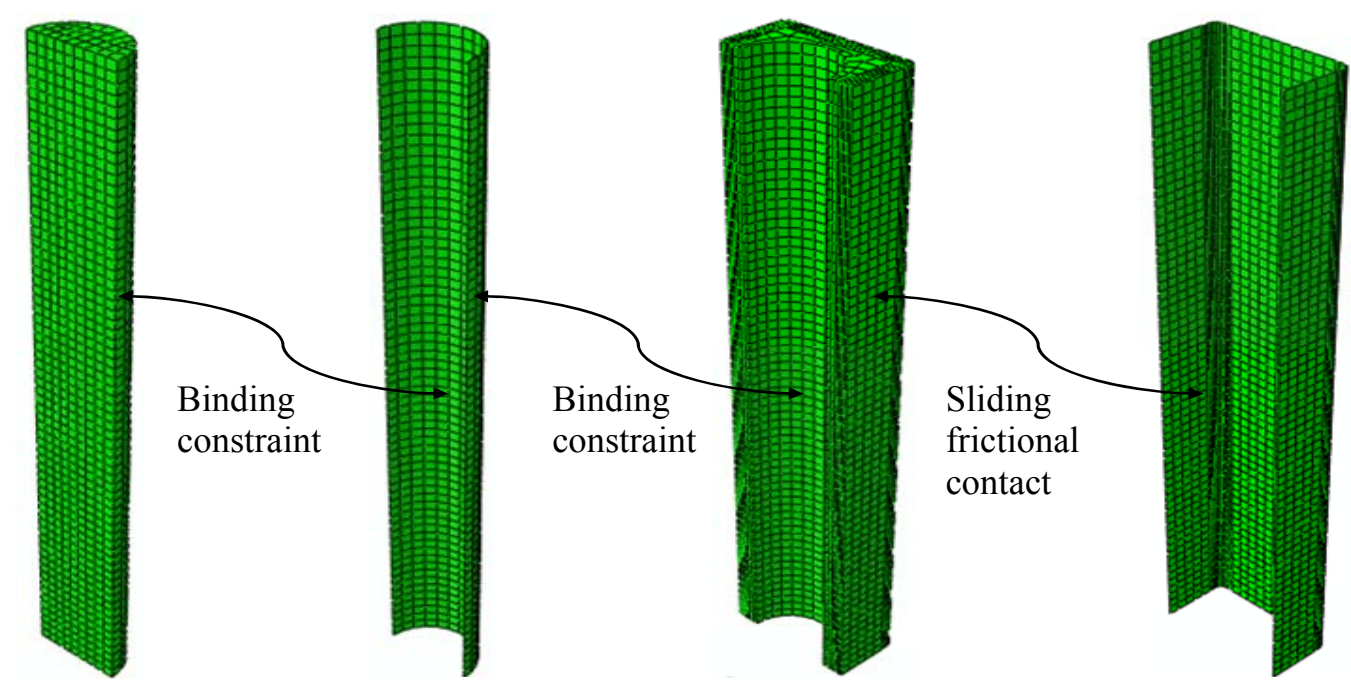

Core concrete

CFRP

Sandwich concrete

Steel tube

Figure 4. Finite Element Model of Specimen

Since the contacts between the loading plates and the top zones of the concrete are only considered in the normal direction, "hard" contact (hard contact) is used to simulate to transmit the reaction force perpendicular to the loading plate between the interfaces. "Shell to solid" provided by ABAQUS 6.7 is applied to contact between steel tube and the loading plate, for the steel tube is simulated by shell element model. Taking into account cooperative deformation of CFRP with core concrete or sandwich concrete, binding constraints (tie) is used to emulate both the interface 
between core concrete and CFRP tube and interface between sandwich concrete and CFRP tube. The model proposed by Liu [12] is applied to simulation of the contact between steel tube and concrete. The contact along the normal direction is hard contact and that along the tangent direction is sliding frictional contact. The friction coefficient is 0.6 and the contact relations among materials are shown in the Figure 4.

\section{RESULTS OF THE ANALYSIS}

\subsection{Comparison of the Ultimate Bearing Capacity.}

Table 1. Comparison of the Ultimate Bearing Capacity

\begin{tabular}{|c|c|c|c|c|c|c|c|c|c|c|}
\hline number & $\begin{array}{c}B \\
(\mathrm{~mm})\end{array}$ & $\begin{array}{c}L \\
(\mathrm{~mm})\end{array}$ & $\begin{array}{c}t \\
(\mathrm{~mm})\end{array}$ & $\begin{array}{c}f_{y} \\
(\mathrm{MPa})\end{array}$ & $\lambda$ & $\alpha$ & $\begin{array}{c}\delta_{c f p} \\
(\mathrm{~mm})\end{array}$ & $\begin{array}{c}N_{u} \\
(\mathrm{kN})\end{array}$ & $\begin{array}{c}N_{u}^{\prime} \\
(\mathrm{kN})\end{array}$ & $\frac{N_{u}^{\prime}}{N_{u}}$ \\
\hline 2600AL50 & 200 & 2600 & 5 & 320 & 45.033 & 0.108 & 0 & 3950 & 3920 & 0.992 \\
\hline 2800AL50 & 200 & 2800 & 5 & 320 & 48.497 & 0.108 & 0 & 3900 & 3889 & 0.997 \\
\hline 3000AL50 & 200 & 3000 & 5 & 320 & 51.962 & 0.108 & 0 & 3750 & 3848 & 1.026 \\
\hline 3200AL50 & 200 & 3200 & 5 & 320 & 55.426 & 0.108 & 0 & 3687 & 3801 & 1.031 \\
\hline 2600AL52 & 200 & 2600 & 5 & 320 & 45.033 & 0.108 & 0.334 & 4086 & 3943 & 0.965 \\
\hline 2800AL52 & 200 & 2800 & 5 & 320 & 48.497 & 0.108 & 0.334 & 3934 & 3901 & 0.992 \\
\hline 3000AL52 & 200 & 3000 & 5 & 320 & 51.962 & 0.108 & 0.334 & 3795 & 3852 & 1.015 \\
\hline 3200AL52 & 200 & 3200 & 5 & 320 & 55.426 & 0.108 & 0.334 & 3690 & 3809 & 1.032 \\
\hline
\end{tabular}

\section{Note:}

The first letter A of specimen No. means axial compression;

The second letter L means long column;

The first Roman numbers 5 behind letters represents that thickness of tube wall is $5 \mathrm{~mm}$;

The second Roman numbers 0, 2 under letters represent that the number of carbon fiber layers around CFRP circular tube is 0 and 2 respectively.

$\mathrm{B}$ represents the outside length of square specimen section,

$\mathrm{L}$ represents the length of the specimen,

$\mathrm{t}$ represents the thickness of steel tube wall,

$f_{y}$ represents the yield strength of steel tube,

$\lambda=2 \sqrt{3} L / B$ represents the slenderness ratios,

$\alpha$ represents steel radio;

$\delta_{c f r p}$ represents the thickness of carbon fiber cloth,

$N_{u}$ and $N_{u}^{\prime}$ represent ultimate compressive strength obtained from specimen experiments and from the finite element method separately.

Table 1 shows the detailed information and ultimate bearing capacity value of specimens of long columns of high-strength concrete filled square steel tube with CFRP circular tube under axial compression corresponding to the experiment. The results of analysis show that the error between calculated values and experimental values of ultimate bearing capacity obtained by nonlinear finite element analysis is less than $10 \%$. The mean and variance of the $N_{u}^{\prime} / N_{u}$ value of concrete filled 
square steel tubes are 1.006 and 0.005 respectively. It shows that the calculated results agree well with the experimental results. Thus, the calculation method which analyzed the mechanical property on long column of high-strength concrete-filled square steel tube with internal CFRP circular tube under axial compression is reliable.

\subsection{Full Range Analysis on Load-Axial Strain}

To study the working mechanism of long columns of concrete-filled square steel tube with inner CFRP circular tube under axial compression, it is essential to analyze the typical curve of load $(\mathrm{N})$-average longitudinal strain $(\varepsilon)$ of long columns under axial compression separately, shown in Figure 5. The curve is divided into four sections: OA segment (elastic stage), AB segment (plastic stage), BC segment (descending stage), and CD segment (rebounding stage). Point A in the curve is the beginning point in which steel tube goes into the plastic stage. Point $\mathrm{B}$ is the point in which the component reaches its ultimate bearing capacity. Point $\mathrm{C}$ is the point in which the role of CFRP is clearly starting to act on the mechanical prosperity of the column. Point D' means a sudden rupture of CFRP circular tube. When the function of core concrete in the finite element method process is extremely unstable, axial deformation of the specimen is comparatively large and there is a large buckling in steel wall. The point $\mathrm{D}$ (the corresponding strain is about $3.5 \varepsilon_{0}-5 \varepsilon_{0}$ ) before point $\mathrm{D}$ is elected to investigate the mechanical properties of concrete before the rupture of CFRP circular tube.

The typical example of long columns of high-strength concrete-filled square steel tube with inner CFRP circular tube under axial compression and that of normal long columns of concrete filled steel tube under axial load are used to compare and analyze the changes in stress and strains of core concrete, steel tube and CFRP circular tube in the whole process so as to investigate their working principles. The calculation parameters of these typical examples are as the follows : $\mathrm{L}=3000 ; \mathrm{B}=$ $200 \mathrm{~mm} ; \mathrm{t}=5 \mathrm{~mm} ; \delta_{\text {cfrp }}=0.334 ;$ Steel $Q_{235}$ and concrete C90 are used.

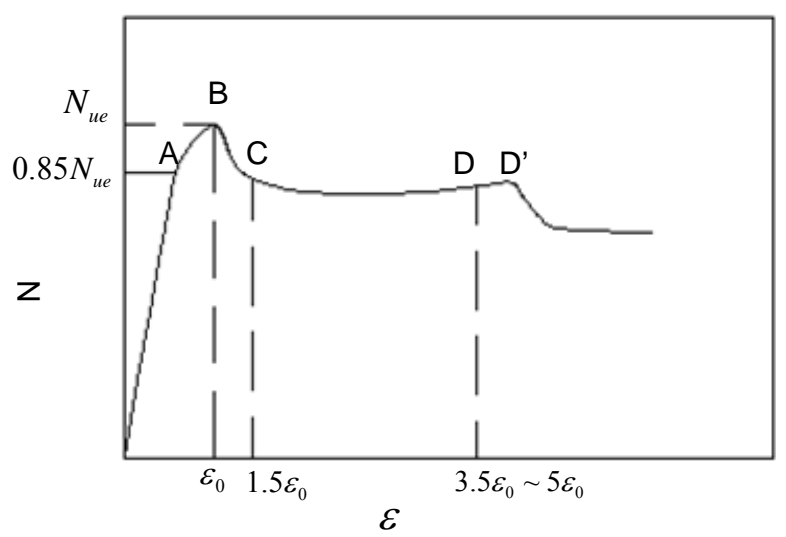

Figure 5. Typical N-e Relation Curve

\subsection{Stress and Strain Analysis of the Core Concrete.}

Figure 6 shows the longitudinal stress (S22) distribution of the core concrete section corresponding to points $\mathrm{A}, \mathrm{B}, \mathrm{C}$ and $\mathrm{D}$ on typical $\mathrm{N}-\varepsilon$ relation curves. The results show that, in the whole process, the core concrete of long columns of high-strength concrete-filled square steel tube with inner CFRP circular tube are subjected to pressure in the total cross section. When the load is small (point A), the steel has no confinement effects on the concrete due to relatively larger Poisson ratio of steel than that of concrete. When the load reaches the ultimate bearing capacity (B point) of the column, the lateral deformation coefficient of concrete is larger than that of steel, because the 
plastic deformation of concrete was formed. The confinement effect of steel on concrete mainly concentrates on the corner of steel tube. Then the load begins to decrease and the confinement performed by steel begins to expand to the flat region. When the load drops to point $C$, the difference of longitudinal stress distribution between core concrete and sandwich concrete starts to be obvious. The longitudinal stress distribution is uneven and the stress of core concrete significantly increases. When arriving at point $\mathrm{D}$, the difference is more obvious and the stress of core concrete continues increasing.

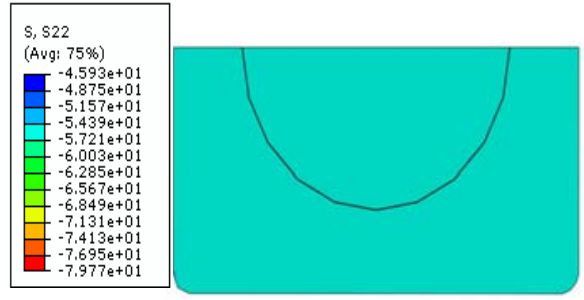

Point A
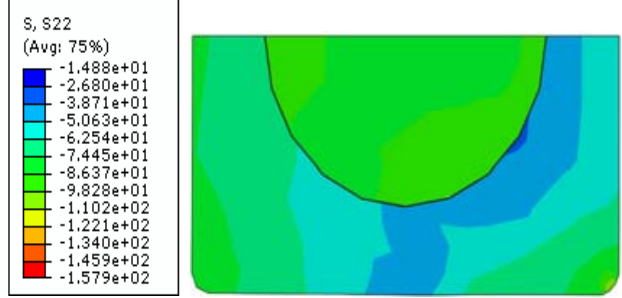

Point C

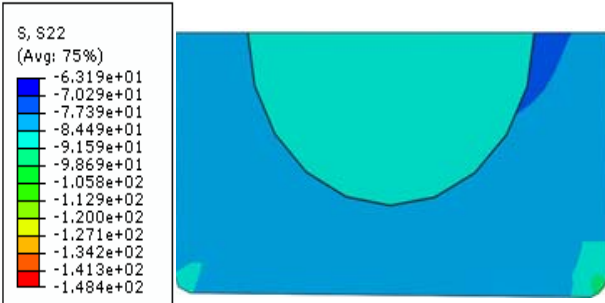

Point B
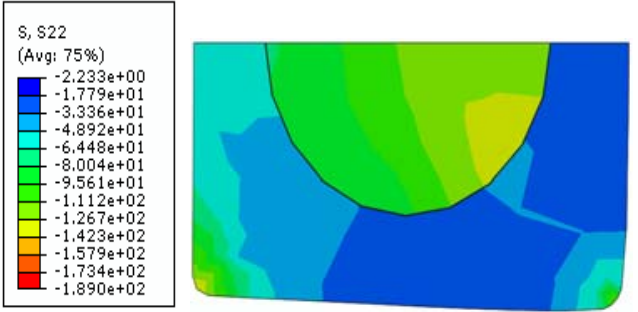

Point D

Figure 6. The Longitudinal Stress Distribution of Sectional Core Concrete in Concrete Filled Square Steel Tube with Inner CFRP Circular Tube

In order to facilitate comparison with ordinary concrete-filled square steel tube similar to the method proposed in Gu et al. [13], Figure 7 shows the longitudinal stress distribution in the cross section of square steel tube concrete columns corresponding to points $\mathrm{A}, \mathrm{B}, \mathrm{C}$ and $\mathrm{D}$. The stress of the core concrete of concrete filled square steel tube is generally less than that of the core concrete of concrete-filled square steel tube with inner CFRP circular tube and CFRP tube played an important role in the Constraint effect on the core concrete.

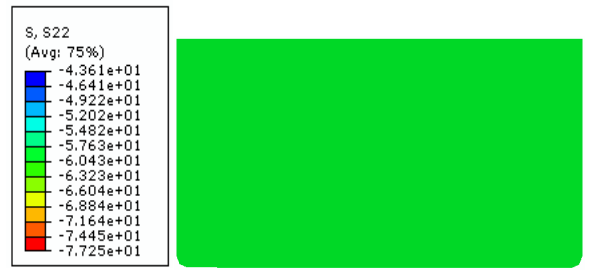

Point A
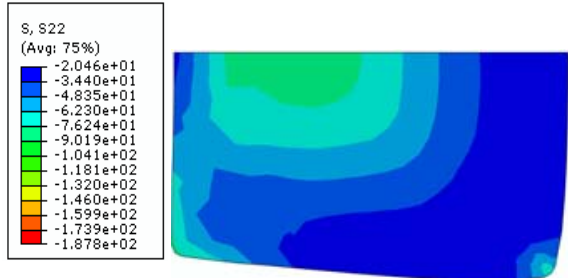

Point C

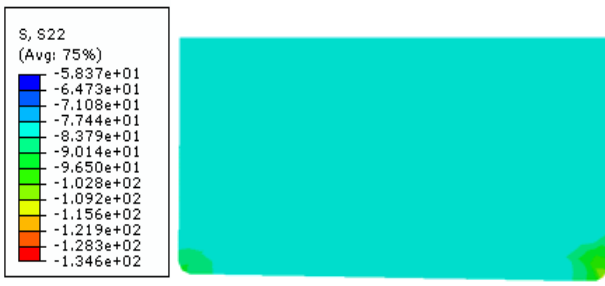

Point B

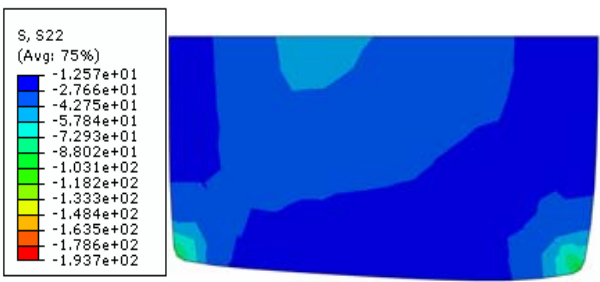

Point D

Figure 7. The Longitudinal Stress Distribution of Sectional Core Concrete in Concrete-Filled Square Steel Tube 
In order to reflect the plastic development of cross section of core concrete directly, Figure 8 and Figure 9 show the longitudinal plastic strain distribution of core concrete of axial long column components. The results show that the plastic development of concrete filled square steel tube with inner CFRP circular tube is slower and the plastic strain at both ends gradually spreads into the mid-span. At point $\mathrm{D}$, the large plastic deformation is formed in the middle of the core concrete section. But the plasticity of core concrete of concrete filled square steel tube developed rapidly, the longitudinal plastic strain in the section begins to be brought forth obviously at point $\mathrm{B}$. It continues to increase and the rate of the increase speeds up at point $\mathrm{C}$.

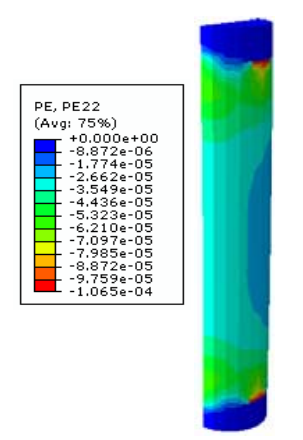

Point A

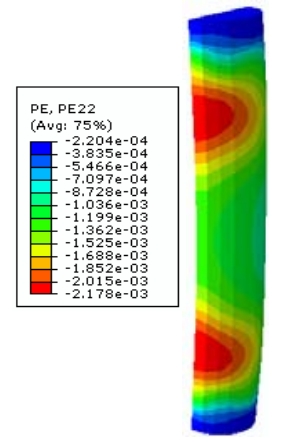

Point B

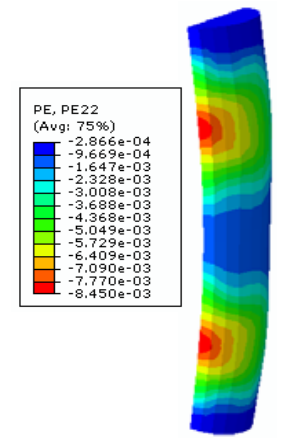

Point C

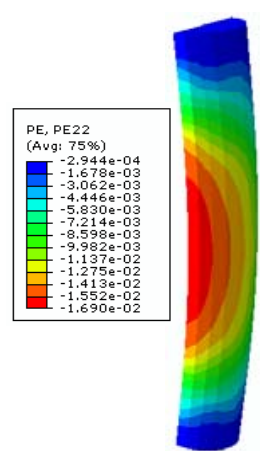

Point D

The Longitudinal Plastic Strain Distribution of Core Concrete

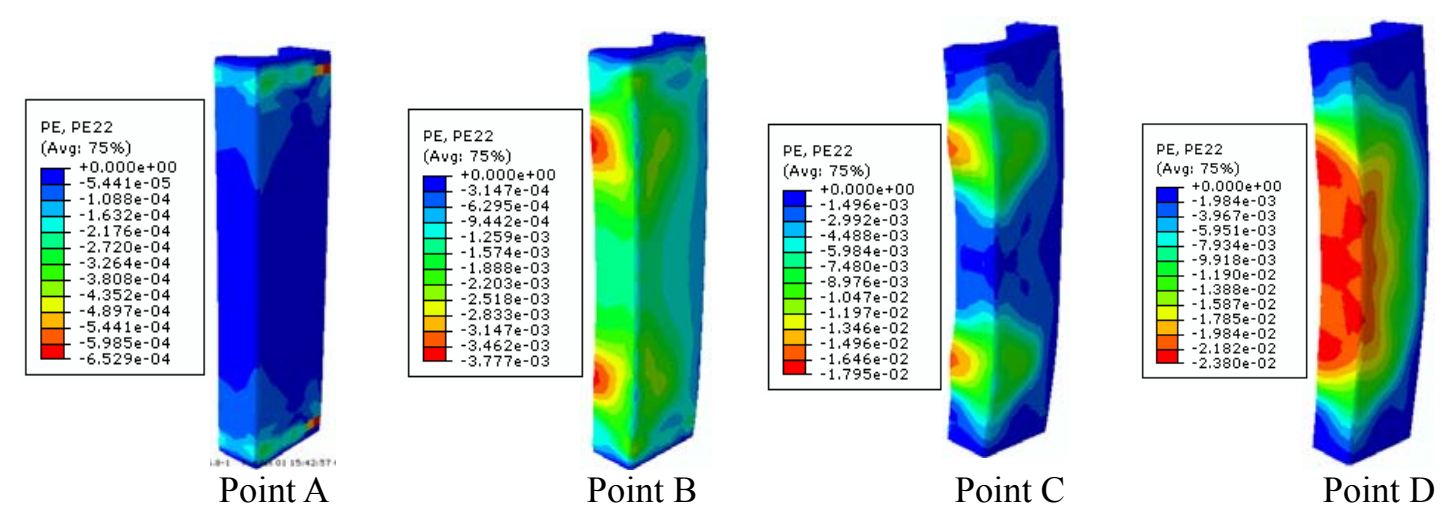

The Longitudinal Plastic Strain Distribution of Sandwich Concrete

Figure 8. The Longitudinal Plastic Strain Distribution of Sectional Core Concrete in Concrete Filled Square Steel Tube with Inner CFRP Circular Tube

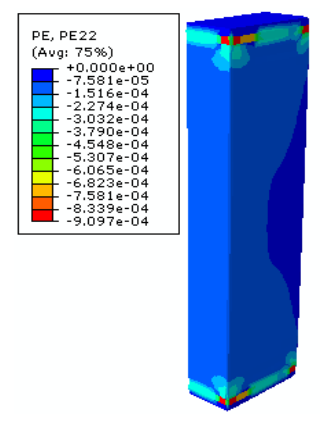

Point A

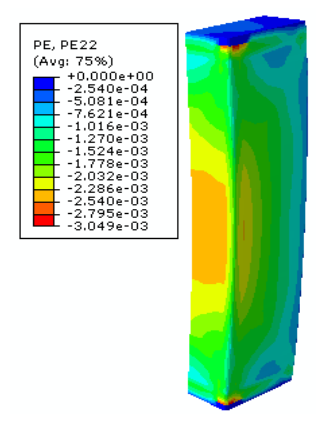

Point B

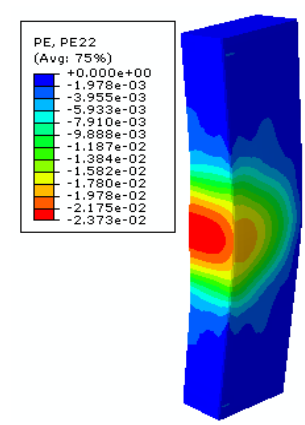

Point C

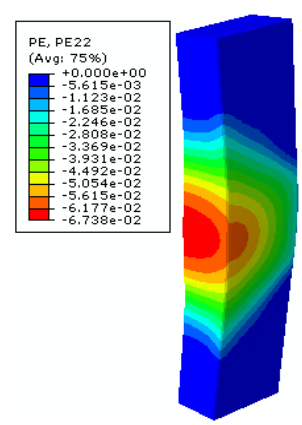

Point D

Figure 9. The Longitudinal Plastic Strain Distribution of Sectional Core Concrete in Concrete Filled Square Steel Tube 


\subsection{Stress Analysis of Steel Tube.}

Since the cold-bending steel tube is used in this paper, the increase of yield strength of steel in corner part of the steel tube is taken into consideration, with its cross section divided into corner region and flat region. Different yield strength and the relevant parameters of plastic development are set to each region. Figure 10 shows the Mises stress distribution of steel of concrete filled square steel tube with internal CFRP circular tube in the whole process of steel under load. The results demonstrate that steel tube does not produce the confinement effect on concrete due to its relatively large Poisson radio when the load is small (point A). As a result, the entire section of steel tube is basically in the elastic state while the strain values of corner region and flat region have reached proportional ultimate value. As steel tube reaches its ultimate bearing capacity (point B), what can be seen from the Mises output values is that the maximum value in corner region has reached the yield value of steel. With the increase of load, the steel tube goes into plastic state and its strain is still rising slowly, while the plastic strain develops fast. So there is the plastic failure in the axial compressive component.
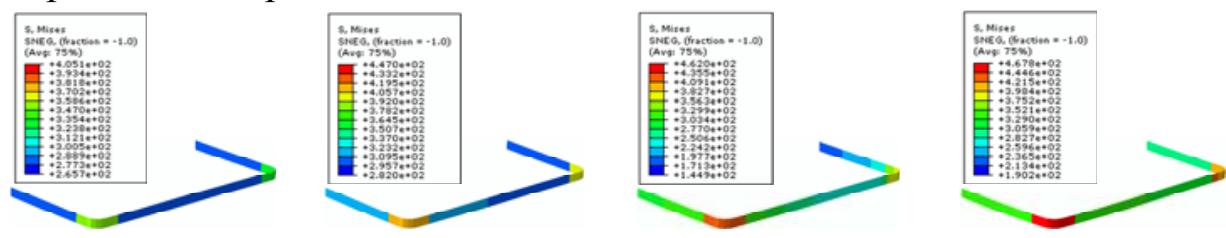

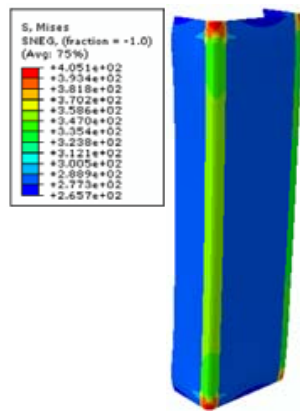

Point A

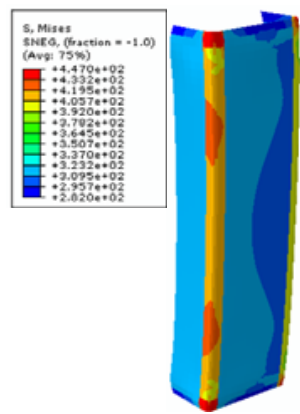

Point B

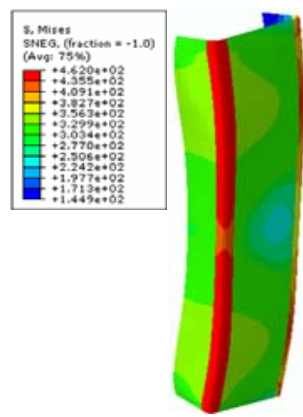

Point C

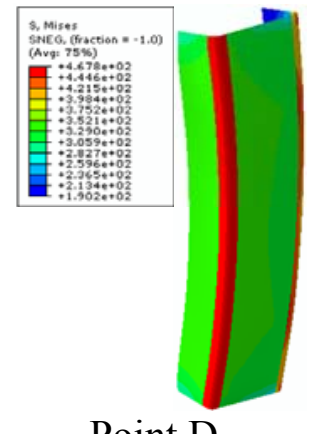

Point D

Figure 10. Mises Stress Distribution of Steel of Concrete Filled Square Steel

Tube with Inner CFRP Circular Tube 


\subsection{Strain Analysis of CFRP}

Figure 11 shows the principal stress vector of CFRP circular tube. It can be seen that the direction of maximum principal stress vector in CFRP is along the longitudinal direction of circular tube. Figure 12 gives the distribution figure of maximum principal stress of CFRP circular tube and the results show that, when the load is small (point A), the distribution of maximum principal stress along longitudinal is uneven. The maximum principal stress is not more than $93.8 \mathrm{Mpa}$ from the output values of principal stress when the CFRP circular tube is under small load. When arriving at its ultimate bearing capacity (point B), the maximum principal stress value of CFRP is $695.3 \mathrm{MPa}$, only one-sixth of its ultimate bearing capacity. CFRP does not play a significant role in the core concrete when the component reaches its ultimate bearing capacity. When the load drops to point $\mathrm{C}$, maximum principal stress of CFRP gradually moves closer to the middle of the span and it also reaches its maximum value $1875 \mathrm{MPa}$. It shows that CFRP circular tube starts to have a significant confinement effect on core concrete. Figure 5 indicates that $\mathrm{N} \sim \varepsilon$ curve starts to rebound from this point $(\mathrm{C})$. As the load increases, the maximum principal stress is also increasing correspondingly and the confinement effect of steel tube on core concrete becomes increasing apparently. When CFRP reaches its ultimate bearing capacity at point $\mathrm{D}$, the confinement effect comes to its extreme.

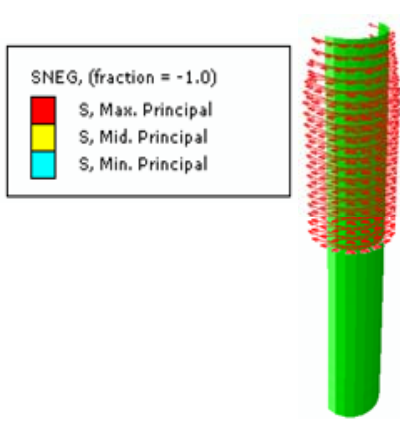

Point A

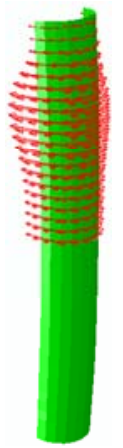

Point B

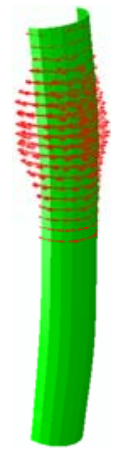

Point C

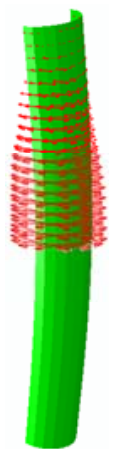

Point D

Figure 11. Distribution of the Principal Stress Vector of CFRP

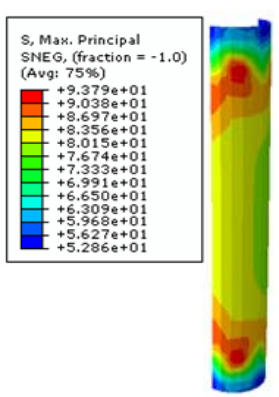

Point A

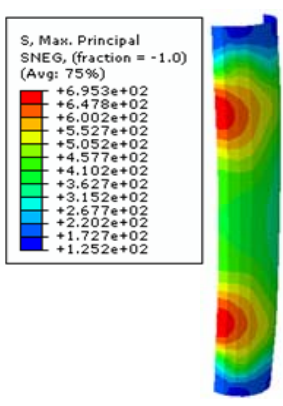

Point B

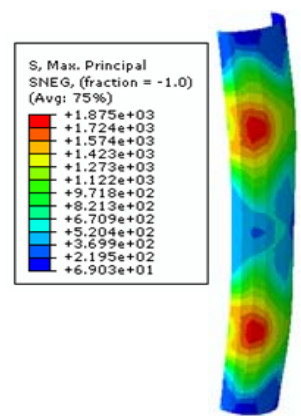

Point C

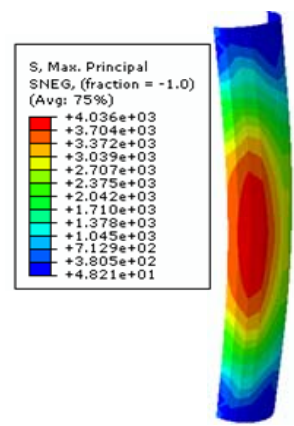

Point D

Figure 12. Distribution of the Maximum Principal Stress of CFRP 


\section{BOUNDARY SLENDERNESS RATIO OF ELASTIC BUCKLING}

\subsection{Calculation of the Bound Slenderness Ratio}

The destruction of concrete-filled steel tubular short column under axial load is the strength failure and the destruction of long concrete-filled steel tubular column is the buckling failure. Buckling failure can be divided into elastic-plastic failure and elastic buckling failure. When the buckling failure occurs and the compression stress is less than the yield strength of the steel, the failure can be defined as the elastic buckling failure. The capacity of components with relatively large slenderness ratio under axial load often depends on stability because of the initial defects. In order to receive the boundary slenderness ratio of elastic buckling of long column, the finite element simulation on long columns (the slenderness ratio $\lambda \leq 138.5$ ) of high-strength concrete-filled square steel tube with inner CFRP circular tube under axial compression is performed in the paper. Because the boundary slenderness ratio is related with the ultimate load and the load-deformation curve after the ultimate load is not a main task of the study, the figure of the load-deformation curve is only included a certain portion after the ultimate load of the specimen. Figure 13 shows the loads $(\mathrm{N})$-the average longitudinal strain $(\varepsilon)$ curve of strength concrete-filled square steel tubular long columns. And its slenderness ratio is less than 138.6. Figure 14 shows the load $(\mathrm{N})$-the average longitudinal strain $(\varepsilon)$ curve of high-strength concrete filled square steel tubular long columns with inner CFRP circular tube with the slenderness ratio corresponding to concrete-filled square steel tube.

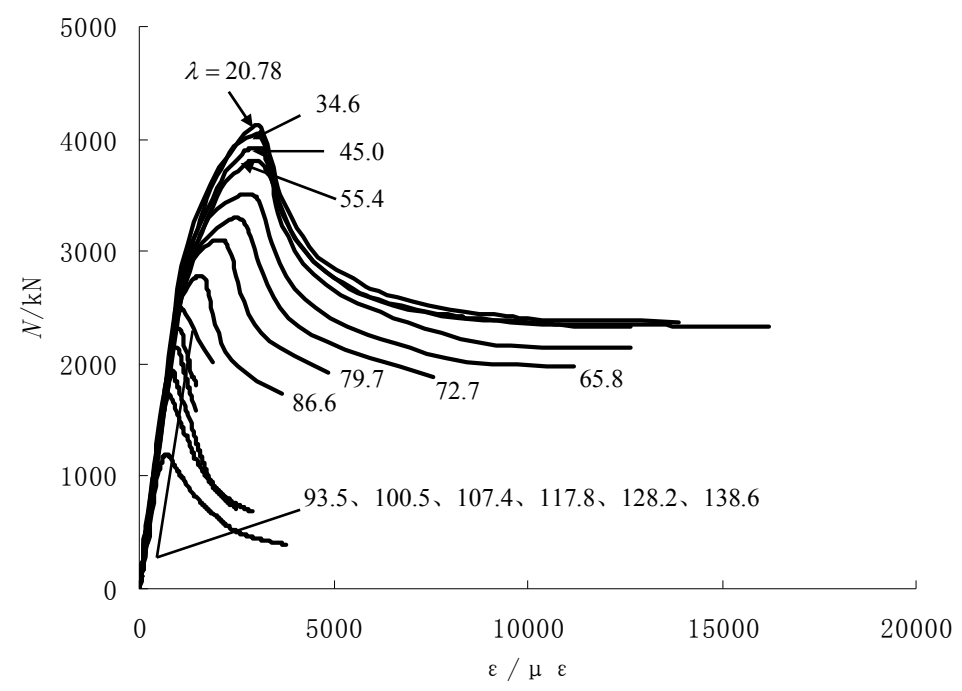

Figure 13. $N-\varepsilon$ Curve of High-Strength Concrete-Filled Square Steel Tubular Long Columns

The ultimate bearing capacity of high-strength concrete-filled steel tubular long columns is defined as the critical force when buckling failure occurs. Figure 13 and Figure 14 show that critical forces of all specimens under axial compression have much to do with slenderness ratio. The smaller the slenderness ratio $\lambda$ is, the greater the critical force is and the greater the limit deformation is. The greater the slenderness ratio $\lambda$ is, the smaller the ultimate deformation is and the critical force smaller is. It is can be seen from Figure 13 when $\lambda$ is $20.78 \sim 86.6$, the columns of concrete-filled square steel tube reach a critical state in the plastic phase of the $\mathrm{N}-\varepsilon$ curve. When $\lambda=93.5 \sim 138.6$, it reaches a critical state in the elastic stage of the $\mathrm{N}-\varepsilon$ curve. So the boundary slenderness ratio of high-strength concrete-filled square steel tubular long columns under axial compression is 93.5 when elastic buckling occurs $(\mathrm{L}=5400 \mathrm{~mm})$. 


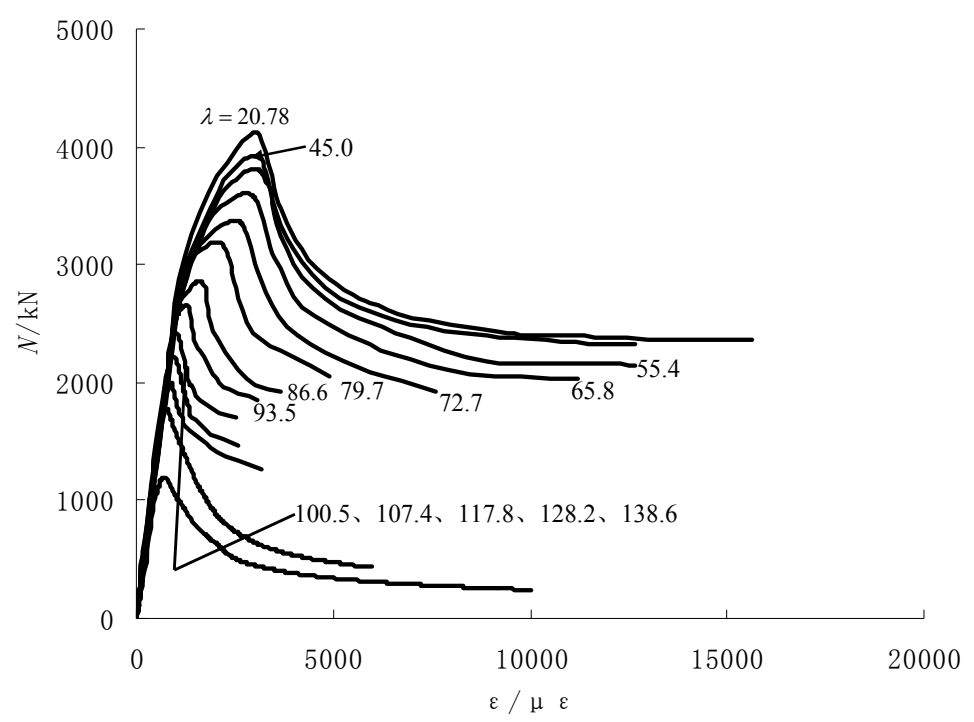

Figure 14. $N-\varepsilon$ Curve of High-Strength Concrete Filled Square Steel Tube with Inner 2 Layers CFRP Circular Tubular Long Columns

It can be seen from Figure 14, when $\lambda=20.78 \sim 93.5$, the columns of high-strength concrete-filled square steel tube with inner CFRP circular tube reach critical state in the plastic phase of the N- $\varepsilon$ curve. When $\lambda=100.5 \sim 138.6$, the specimens reach critical state in the elastic stage of the N- $\varepsilon$ curve. So the boundary slenderness ratio of columns studied in the paper under axial compression is 100.5 when elastic buckling occurs $(\mathrm{L}=5800 \mathrm{~mm})$.

Figure 15 shows the load $(\mathrm{N})$-deflection of mid-span $(\Delta)$ relationship curve of components of high-strength concrete-filled square steel tube under axial compression. It is shown in Figure 15 that, as slenderness ratio increases, the deflection $(\Delta)$ gradually increases, when the components reach its critical state. The anti-lateral stiffness and stability of components of high-strength concrete-filled square steel tube under axial compression decrease as slenderness ratio increases. At the same time, the deflection $(\Delta)$ of components $(\lambda \leq 86.6)$ with plastic buckling begins to span obviously when it arrives at $60 \% \sim 70 \%$ of critical force, while the deflection $(\Delta)$ of components $(\lambda \geq 93.5)$ with elastic buckling starts at the beginning of loading.

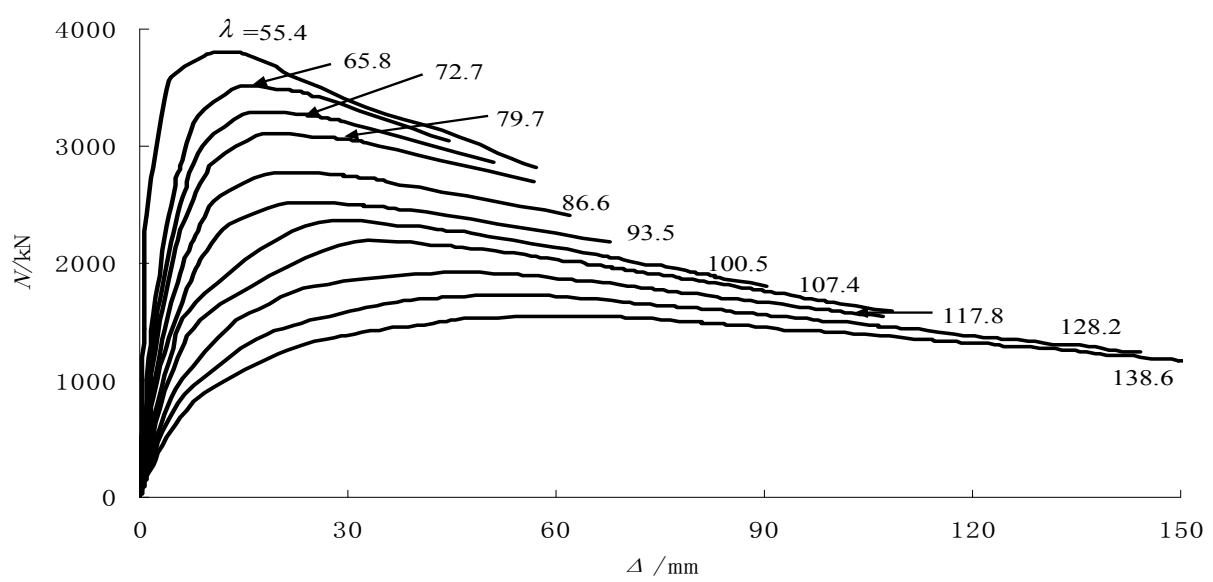

Figure 15. N- $\Delta$ Relationship Curve of High-Strength Concrete Filled Square Steel Tubular Columns 


\subsection{Theoretical Validation of Boundary Slenderness Ratio}

Zhong and Han [14] adopted numerical methods to calculate the load-deformation curve of the components under axial load and defined that the strength in the end of elastic stage of the curve is combinational proportional limit $f_{s c p}$. The reduced stress of steel has reached its proportional limit and the strain of component is proportional strain $\varepsilon_{s c p}$. It is defined that $f_{s c y}$ is the standard strength value when the component reaches its ultimate bearing capacity. These parameters $f_{s c p} / f_{s c y}$ and $\varepsilon_{s c p}$ do not depend on steel ratio and strength grade of concrete, but on the yield point of steel. It is due to the one-way force to which the steel and concrete at this stage are subjected, without the confining force, as shown in Han [3].

According to analysis results by numerical calculation of Zhong and Han [14], the expression of parameters can be calculated as follows:

$$
\begin{aligned}
& f_{s c y}=\left(1.212+B \xi+C \xi^{2}\right) f_{c k} \\
& f_{s c p}=\left[0.263\left(f_{y} / 235\right)+0.365\left(30 / f_{c u}\right)+0.104\right] f_{s c y} \\
& \varepsilon_{s c p}=3.01 \times 10^{-6} f_{y}
\end{aligned}
$$

Among: $\mathrm{B}=0.131 f_{y} / 235+0.723, \mathrm{C}=-0.07 f_{c k} / 20+0.0262$

$\xi$ is confine coefficient of the concrete-filled steel tube

The article defines that the combinational proportional load $N_{s c p}$ is equal to the $f_{s c p} \times A_{s c}$ (multiplication of combinational proportional limit and the cross-sectional area of the component). If the critical force in damage is greater than the combinational proportional load of components under axial load, the damage belongs to the plastic buckling. While the critical force in buckling damage is less than the combinational proportional load of component under axial load, the damage belongs to elastic buckling. The calculated values can be obtained from interrelated values of examples in this paper.

$$
\begin{array}{ll}
f_{s c y}=106.085 \mathrm{MPa}, & f_{s c p}=62.463 \mathrm{MPa}, \\
\varepsilon_{s c p}=978.25 \times 10^{-6}, & N_{s c p}=2498.5 \mathrm{KN}
\end{array}
$$

The critical force of components of high-strength concrete-filled square steel tube with the buckling failure is $2483 \mathrm{KN}$ in this article when the slenderness ratio is $93.5(\mathrm{~L}=5400 \mathrm{~mm})$ which is less than the combinational proportional load $N_{s c p}$ obtained by theoretical calculation. The proportional strain is $993.47 \times 10^{-6}$ equivalent to the theoretical calculation value. It proves the correctness of the calculation. The critical force of columns of high-strength concrete-filled square steel tube with internal CFRP circular tube with the buckling failure is $2419 \mathrm{KN}$ in this paper when the slenderness ratio is 100.5 ( $\mathrm{L}=5800 \mathrm{~mm}$ which is less than the theoretical calculation value. The proportional strain is $957.47 \times 10^{-6}$. It indicates that the buckling damage is elastic buckling. 
The theoretical formula of limit slenderness radio of long columns of concrete-filled steel tube proposed by Zhong and Han [14] when elastic buckling occurs is shown as follows:

$$
\lambda_{p}=1811 / \sqrt{f_{y}}
$$

To put the yield strength of steel into the expression can be obtained that the theoretical limit slenderness ratio of elastic buckling is $\lambda_{p}=101.2$. In the paper, the limit slenderness ratio is 93.5 when elastic buckling occurs on long column of concrete-filled square steel tube under axial compression. The limit slenderness ratio is 100.5 when elastic buckling occurs on long column of concrete-filled square steel tube with inner CFRP circular tube under axial compression. The difference between the calculated limit slenderness ratio and that of finite element simulated is small and shows the accuracy of the calculation.

\section{CONCLUSIONS}

(1) The finite element analysis on long columns of high-strength concrete-filled square steel tube with inner CFRP circular tube under axial load can be conducted by ABAQUS 6.7 perfectly. And the results of finite element analysis show a good agreement with the experimental results.

(2)According to the analysis on the core concrete stress of long columns of high-strength concrete-filled square steel tube with internal CFRP circular tube under axial compression, when the columns achieve the ultimate bearing capacity, the longitudinal stress distribution of sandwich concrete and that of core concrete are uneven and the core concrete is the primary part to bear the load.

(3)When long columns of high-strength concrete-filled square steel tube with internal CFRP circular tube reaches the ultimate bearing capacity, steel tube has reached its yield limits.

(4)The analysis results of long columns of high-strength concrete-filled square steel tube with inner CFRP circular tube under axial compressive show that, the confinement effect of CFRP on core concrete is small before components reach the ultimate bearing capacity. After the ultimate bearing capacity, CFRP circular tube begins to play a significant role in confinement effect on the core concrete.

(5)According to the results of finite element simulation on the specimens, the critical forces of all specimens under axial compression are depended on the slenderness ratio. The smaller the slenderness ratio $\lambda$ is, the greater the critical force is and the greater the limit deformation is.

(6) The limit slenderness ratio is 93.5 when elastic buckling occurs on the long column of concrete-filled square steel tube under axial compression. The limit slenderness ratio is 100.5 when elastic buckling occurs on the long column of concrete-filled square steel tube with inner CFRP circular tube under axial compression. These results have been verified by theoretical calculation. 


\section{ACKNOWLEDGEMENTS}

This project was supported by National Science Foundation of China (50678106), Shenyang Talent Development Fund (2009140403038), Liaoning BaiQianWan Talents Program (2010921001), Liaoning Talents Program (LR2011014) and Technology Development Program of Ministry of Housing and Urban-Rural Development (2011-k3-23).

\section{REFERENCES}

[1] Cai, S.H. and Gu, W.L., "Behaviour and Ultimate Strength of Long Concrete-Filled Steel Tubular Columns", Journal of Building Structures, 1985, Vol. 6, No. 1, pp. 32-40.

[2] Tan, K.F., Pu, X.C. and Cai, S.H., "The Study of Mechanics and Ultimate Bearing Intensity of Super High-strength Concrete Filled Steel Tube", Architecture Structure Journal, 1999, Vol. 20, No. 1, pp. 10-11.

[3] Han, L.H., "Technology of Modern Concrete Filled Steel Tube", China Architecture \& Building Press, 2007.

[4] Zhong, S.T., "Research and Application of Unified Theory of Steel Concrete", Tsinghua University Press, 2006.

[5] Liang, Q.Q., Uy, B. and Liew, J.Y.R., "Strength and Ductility of Concrete-filled Thin-walled Steel Box Columns with Local Buckling Effects", Special Issue Australian Journal of Structural Engineering, 2007, Vol. 7, No. 2, pp. 145-156.

[6] Liang, Q.Q., Uy, B. and Liew, J.Y.R., "Local Buckling of Steel Plates in Concrete-filled Thin-walled Steel Tubular Beam-columns", Journal of Constructional Steel Research, 2007, Vol. 63, No. 3, pp. 396-405.

[7] Liang, Q.Q., Uy, B. and Liew, J.Y.R., "Nonlinear Analysis of Concrete-filled Thin-walled Steel Box Columns with Local Buckling Effects", Journal of Constructional Steel Research, 2006, Vol. 62, No. 6, pp. 581-591.

[8] Mursi, M. and Uy, B., "Behaviour and Design of Fabricated High Strength Steel Columns Subjected to Biaxial Bending, Part 1: Experiments", Journal of Advanced Steel Construction, Hong Kong Institute of Steel Construction, 2006a, Vol. 2, No. 4, pp. 286-315.

[9] Mursi, M. and Uy, B., "Behaviour and Design of Fabricated High Strength Steel Columns Subjected to Biaxial Bending, Part 2: Analysis and Design Codes", Journal of Advanced Steel Construction, Hong Kong Institute of Steel Construction, 2006b, Vol. 2, No. 4, pp. 316-354.

[10] Li, G.C., Ma, L. and Yang, J.L., "Bearing Capacity of Short Columns of High-Strength Concrete Filled Square Steel Tubular with Inner CFRP Circular Tubular under Axially Compressive Load", Natural Science, Journal of Shenyang Jianzhu University, 2008, Vol. 24, No. 1, pp. 62-64.

[11] Abdel-Rabman and Sivakumaran, K.S., "Material Properties Models for Analysis of Cold-formed Steel Members", Journal of Structural Engineering, 1997, Vol. 123, No. 9, pp. 113-1143.

[12] Liu, W., "The Study of Working Mechanism of Concrete Filled Steel Tube under Partial Compression", Journal of Harbin Institute of Technology, 2003, Vol. 35, pp. 63-66.

[13] Gu, W.P., Cai, S.H. and Feng, W.L., "The Study of Function and Ultimate Bearing Intensity of High-strength Concrete Filled Steel Tube", Architecture Science, 1991, Vol. 7, No. 1, pp. 23-24.

[14] Zhong, S.T. and Han, L.H., "Steel Tube Concrete Mechanic", Dalian University of Technology Press, 1996. 